\title{
EDUCACIÓN EN MEDIOS Y COMPETENCIA EMOCIONAL
}

\author{
Joan Ferrés i Prats (*)
}

SÍNTESIS: La eficacia de la educación en medios está condicionada por la capacidad de los educadores para comprender a fondo lo que significa la experiencia de ser espectador, lo que implica tomar conciencia del peso de las emociones y del inconsciente en esta experiencia.

Lo que nos dice hoy la neurociencia sobre el cerebro emocional ayuda a comprender la fuerza socializadora de los medios audiovisuales, como se comprueba en mecanismos comunicativos como el product placement 0 el value placement.

También facilita esta comprensión el hecho de analizar la experiencia audiovisual a la luz de lo que los psicólogos conocen como fenómenos entre dos luces, fenómenos a medio camino entre la razón y la emoción, entre la conciencia y el inconsciente, entre lo primitivo y lo evolucionado.

Como todos estos fenómenos, la experiencia audiovisual es decisiva en la construcción o modelado de la identidad personal, precisamente a partir de los modelos de comportamiento que ofrece para el consumo.

En definitiva, sólo desde la competencia emocional, desde la comprensión de la fuerza de las emociones en la experiencia audiovisual, puede impartirse una educación en medios que sea eficaz.

SÍNTESE: A eficácia da educação em meios está condicionada à capacidade dos educadores para compreender a fundo o que significa a experiência de ser espectador, o que implica tomar consciência do peso das emoções e do inconsciente nesta experiência.

O que nos diz hoje a neurociência sobre o cérebro emocional ajuda a compreender a força socializadora dos meios audiovisuais, como se comprova em mecanismos comunicativos como o product placement ou $o$ value placement.

Também facilita esta compreensão o fato de analisar a experiência audiovisual à luz do que os psicólogos conhecem como fenômenos entre duas luzes, fenômenos a meio caminho entre a razão e a emoção, entre a consciência e o inconsciente, entre o primitivo e o evolutivo.

Como todos estes fenômenos, a experiência audiovisual é decisiva na construção ou modelado da identidade pessoal, exatamente a partir dos modelos de comportamento oferecidos para o consumo.

(*) Profesor de Estudios de Comunicación Audiovisual de la Universidad Pompeu Fabra de Barcelona, España. 
Definitivamente, somente a partir da competência emocional, da compreensão da força das emoções na experiência audiovisual, pode ministrar-se uma educação em meios que seja eficaz.

\section{INTRODUCCIÓN}

En el Seminario Internacional que se celebró en Sevilla en febrero de 2002, la UNESCO definió los parámetros que habría que tener en cuenta para un adecuado planteamiento de la educación en comunicación (EC) como disciplina autónoma:

- Mediante la educación en comunicación se pretende enseñar y aprender sobre los medios de comunicación, más que con esos medios.

- La educación en comunicación comprende el análisis crítico y la producción creativa.

- La educación en comunicación puede y ha de tener lugar tanto en el ámbito de la educación formal como en el de la no formal. En consecuencia, ha de afectar de igual modo a los niños y a los adultos.

- La educación en comunicación ha de promover el espíritu de comunidad y de responsabilidad social, así como la autonomía personal.

Son criterios claros y fácilmente asumibles por la mayor parte de los profesionales de la enseñanza que son sensibles a este problema. Las dudas pueden aparecer, si acaso, cuando se trata de definir qué es lo que hay que enseñar sobre los medios, qué comporta el concepto de análisis crítico, o cómo hay que impartir esa enseñanza.

Y es que, si es un problema que en la mayoría de los centros no se imparten enseñanzas relacionadas con la educación en medios, también lo es que cuando se imparten no se hace de la manera adecuada.

A mi entender, el error principal de algunos profesionales de la enseñanza que instruyen sobre contenidos relacionados con la educación en medios consiste en marginar dimensiones fundamentales en la experiencia del consumo de medios. En concreto, las dimensiones relacionadas con la emotividad y el inconsciente. 
Es imposible encarar de manera eficaz la educación en medios si no se analiza en profundidad lo que comporta ser espectador, si no se comprende por qué atraen los medios de masas audiovisuales, qué necesidades satisfacen y de qué manera ejercen su influencia socializadora. De eso se deriva que es irrealizable afrontar de manera apropiada la educación en medios sin una adecuada competencia emocional, es decir, sin un conocimiento en profundidad de cómo funciona el cerebro emocional y de cómo influye en el consumo de mensajes audiovisuales.

\section{A VUELTAS CON EL CEREBRO EMOCIONAL}

Una de las exigencias en la que más insisten los educadores cuando afrontan la educación en medios es la de formar a los ciudadanos en el sentido crítico. Se da por sentado que dicho sentido comporta un cambio sustancial en la manera de ser espectador, y se sobreentiende que tal cambio se manifiesta sobre todo en la capacidad de utilizar la reflexión donde antes había emoción, es decir, en la capacidad de sustituir la emotividad por la racionalidad.

En una cultura como la occidental, caracterizada por la tendencia a sobredimensionar la racionalidad y la conciencia, y, a su vez, por extremar las reticencias ante las emociones y el inconsciente, es lógico que abunden las restricciones ante unos medios de masas audiovisuales que se caracterizan por su incidencia en la emotividad y en el inconsciente. Y que, si acaba por aceptarse la necesidad de una educación en medios, sea precisamente para conseguir que se impongan la racionalidad y la conciencia donde antes reinaban la emotividad y el inconsciente.

El papel que se ha atribuido a las emociones en la cultura occidental ha variado mucho a lo largo de los siglos. En las últimas décadas, desde el momento en que el cognitivismo se convirtió en el sistema dominante para explicar los procesos mentales, las emociones comenzaron a ser marginadas. No había espacio para ellas. Considerada la mente como un ordenador (computador), no hacía falta recurrir a las emociones para explicar su funcionamiento.

En una fase posterior, los teóricos del cognitivismo empezaron a prestar atención a las emociones, pero para someterlas al dictado de la racionalidad, considerándolas como un simple apéndice de la mente racional. Las emociones fueron redefinidas como procesos cognitivos fríos, desprovistos de todo contenido pasional. Para el cognitivista una 
emoción no se diferenciaba de un acto de cognición: las emociones eran sólo pensamientos sobre las situaciones.

Algo similar ocurrió con el inconsciente. Resulta curioso, porque fueron los cognitivistas los que acuñaron el concepto de «inconsciente cognitivo» para indicar que una gran parte de la actividad de la mente se produce fuera del alcance de la conciencia. Pero obviaron, y en muchos casos rechazaron el inconsciente freudiano o dinámico, entendido como depósito de las pulsiones originarias, instintivas, y de las pulsiones reprimidas no accesibles a la conciencia.

Las cosas comenzaron a cambiar. Hoy sabemos por la neurobiología que las emociones y el inconsciente tienen un peso excepcional en la mayor parte de las decisiones y de las creencias humanas. Lo sabemos desde la neurociencia. Los neurobiólogos hablan hoy explícitamente de «las lastimosas consecuencias» que se derivan del tratamiento que la teoría cognitivista ha hecho de las emociones y del inconsciente (LeDoux,1999, p. 43).

LeDoux, neurobiólogo estadounidense, es tajante cuando afirma que «la cognición y la emoción [...] parecen funcionar a nivel inconsciente, y al nivel consciente únicamente llegan los resultados de los procesos cognitivos y emocionales, y sólo en algunas ocasiones» (ídem, p. 23). Y más adelante: «es en el inconsciente emocional donde tiene lugar gran parte de la actividad emocional del cerebro» (ídem, p. 71).

La reivindicación que hace LeDoux de algunos conceptos postulados por Freud se pone de manifiesto en esta cita: «Freud tenía razón cuando describió la conciencia como la punta del iceberg mental». La cita debería resultar inquietante para los educadores, y, en general, para el ámbito académico. Si la mente humana es sobre todo emoción e inconsciente, si los medios de masas audiovisuales inciden de manera prioritaria en las emociones y en el inconsciente, y, finalmente, si el mundo académico tiende a centrar todas sus aproximaciones a los medios en la racionalidad y en la conciencia, estamos malgastando esfuerzos y errando las tentativas.

\section{MODULARIDAD CEREBRAL}

La modularidad cerebral (la relación entre cerebro emocional y cerebro racional) se expresa mediante un complejo juego de interacciones. Los módulos interaccionan entre sí, para bien o para mal. 
Es en este sentido que hoy afirman los especialistas: «el sentimiento es un componente integral de la maquinaria de la razón» (Damasio, 1996, p. 9). «Determinados aspectos del proceso de la emoción y del sentimiento son indispensables para la racionalidad» (ídem, p. 10). El despliegue efectivo de las estrategias de razonamiento depende, en gran medida, de la capacidad continuada de experimentar sentimientos.

Ahora bien, que los módulos se necesiten para un adecuado funcionamiento del sistema global no significa que no puedan actuar de manera autónoma, independiente: «anatómicamente hablando, el sistema emocional puede actuar independientemente del neocórtex. Hay ciertas reacciones y recuerdos emocionales que tienen lugar sin la más mínima participación cognitiva consciente». Esa necesaria integración «no significa que las emociones y los sentimientos no puedan causar estragos en los procesos de razonamiento en determinadas circunstancias. La sabiduría tradicional nos dice que pueden, e investigaciones recientes del proceso normal de razonamiento también revelan la influencia potencialmente dañina de los sesgos emocionales» (ibídem). Los neurobiólogos hablan en estos casos de «secuestro de la racionalidad» (Goleman, 1997).

Y es que el cerebro emocional, cuando actúa de manera autónoma, recurre a unos mecanismos diferenciados, que, una vez más, resultan similares a los que había descrito la psicología dinámica. «Si una determinada entidad en el mundo exterior es un componente de una escena en la que otro componente era una cosa buena o mala, es decir, si excitó una disposición innata, el cerebro puede clasificar la entidad para la que de forma innata no se había establecido ningún valor como si también fuera valiosa, tanto si lo es como si no. El cerebro extiende un tratamiento especial a esta entidad simplemente porque está cerca de la que, con seguridad, es tan importante. Se puede denominar a esto gloria reflejada, si la nueva entidad está cerca de una cosa buena, o culpable por asociación, si está cerca de una cosa mala. La luz que resplandece sobre un objeto importante, genuino, sea bueno o malo, lucirá también sobre su compañía» (Damasio, 1996, pp. 116-117).

Puede observarse que Damasio recupera en esta descripción el concepto del pensamiento mágico de Freud, pensamiento primario, asociativo, transferencial. Si la mente racional confiere sentido y valor a las realidades mediante relaciones de causa y efecto, el cerebro emocional lo confiere mediante estructuras de asociación o de transferencia. 
Sólo desde el pensamiento mágico o transferencial puede comprenderse la experiencia de ser espectador. Es aplicando estructuras de transferencia como nos identificamos con el personaje de una película o como proyectamos sentimientos de agresividad hacia otro. Es aplicando estructuras de asociación o de transferencia (gloria reflejada) como asignamos valor positivo a un producto por el simple hecho de que aparece vinculado a un personaje positivo, interpretado a su vez por un actor o por una actriz atractivos.

\section{DEL PRODUCT PLACEMENT AL VALUE PLACEMENT}

La cantidad de dinero que se dedica a la inserción de productos en momentos clave de las películas y de las series televisivas (estrategia conocida como product placement) es una muestra del peso de las emociones y del inconsciente en la experiencia del consumo audiovisual. Si se realizan estas inversiones es porque se sabe que resultan rentables. Y la normativa que regula tal estrategia comercial pone de manifiesto los mecanismos específicos mediante los que se mueven las emociones y el inconsciente.

La prensa escrita informaba recientemente de la primera experiencia conocida de aplicación del product placement a la literatura. La veterana escritora Fay Weldon llegó a un acuerdo con Bulgari para escribir una novela patrocinada por esta firma de joyería. Bulgari ofreció una generosa cantidad a la escritora. Como contrapartida, ésta se comprometió a hacer aparecer el nombre de la marca un buen número de veces. De hecho, hasta en el título: The Bulgari Connection ${ }^{1}$.

Las empresas especializadas en el product placement audiovisual tienen unos curiosos baremos para medir lo que pueden pagar a las productoras por la inclusión de sus productos. Pagan más si en la historia el producto queda asociado a un personaje principal que a uno secundario. Pagan más si el personaje va a ser interpretado por una estreIla que si lo va a ser por un actor o una actriz poco conocidos. Pagan más si el producto va a aparecer en un momento cumbre del filme o en otro más anodino...

Esta regulación demuestra que los especialistas en product placement conocen a la perfección la manera cómo construimos, cómo

1 Diario La Vanguardia, 9 de septiembre de 2001, p. 55. 
conferimos sentido y valor a la realidad cuando la racionalidad está aparcada. En otras palabras, las técnicas del product placement son una nueva muestra de la construcción del sentido y del valor mediante mecanismos inconscientes, asociativos, contaminantes, que burlan la razón.

En definitiva, el product placement representa un excelente negocio para las productoras de cine y de televisión (ahora parece que también para algunos escritores), y para las empresas que desean promocionar sus productos, y una jugada manipuladora para los receptores, condenados a ser tratados como consumidores incluso cuando no quieren ser más que espectadores o lectores.

Sorprende que los especialistas en product placement conozcan tan a fondo los mecanismos inconscientes mediante los que se puede conferir sentido y valor a los productos en los medios de comunicación de masas, y que los educadores seamos tan poco conscientes del hecho de que estos mismos mecanismos están funcionando siempre para la construcción de valores por parte de los espectadores.

Y es que habría que hablar de un value placement, del mismo modo que lo hacemos de un product placement. Son estrategias muy similares y se rigen por los mismos parámetros expresivos, aunque el emplazamiento de valores a menudo no sea intencional y nadie cobre por su uso. Intencionalmente o no, los medios de masas audiovisuales venden valores y contravalores, sin otro esfuerzo que el de asociarlos a emociones positivas o negativas.

Bastan algunos ejemplos. Podría decirse que en el cien por cien de los relatos publicitarios se premia con una felicidad sin límite a todos aquellos que han adquirido el producto adecuado, de manera que en la mente del receptor la felicidad acaba siendo asociada al consumismo.

En la misma línea abundan los relatos cinematográficos y televisivos, en los que se premia con la chica deseada al personaje más competitivo, al más ambicioso, al más individualista, al más obsesionado por el triunfo, con lo que esos valores o contravalores quedan reforzados en la mente del espectador.

La presencia todavía abundante de mujeres-objeto o de chicas-florero en la televisión y en la publicidad, refuerza el estereotipo de 
que al hombre le corresponde mirar y a la mujer ser mirada, así como la tendencia de que la mujer debe ser sumisa, pasiva, el premio del varón.

Un último ejemplo: en cantidad todavía excesiva de relatos televisivos y cinematográficos, se premia con el éxito narrativo a los personajes que recurren a soluciones violentas para resolver los conflictos, de manera que en los esquemas mentales del espectador se va reforzando la convicción de que la violencia es el sistema más eficaz para solventar dichos conflictos.

$\mathrm{Ni}$ en el product placement ni en el value placement hay argumentación ni razonamiento. Los productos y los valores adquieren sentido positivo o negativo por su simple asociación con emociones positivas o negativas. La diferencia está en que, mientras los especialistas en productos conocen y dominan estos mecanismos, los educadores (supuestos especialistas en valores) no somos conscientes ni de su existencia ni de su potencialidad socializadora.

\section{FENÓMENOS ENTRE DOS LUCES}

Para seguir avanzando en la comprensión de lo que comporta la experiencia de ser espectador en una sociedad mediática, puede resultar operativo incluir dicha experiencia en el marco de lo que en psicología se conoce como fenómenos entre dos luces. Con esta expresión los psicólogos se refieren a experiencias que se sitúan en una posición intermedia entre la conciencia y el inconsciente, entre lo primitivo y lo evolucionado, entre lo racional y lo irracional, entre lo real y lo irreal. Se incluyen fenómenos como los sueños, las ilusiones, la fantasía, los chistes, el arte, la poesía, la religión... (Erdelyi, 1990, p. 151).

Lo que caracteriza a los fenómenos entre dos luces es que son paradójicos. Por una parte son regresivos, en el sentido de que implican contenidos de carácter infantil y estilos psicológicos también infantiles (ibídem). Suponen una disminución del peso de la racionalidad y de la conciencia, y, en consecuencia, un incremento del peso de la emotividad y del inconsciente. Es por eso por lo que se les considera a medio camino, «entre dos luces».

Lo que hace que sean paradójicos es que, siendo como son regresivos, pueden ser madurativos. Se pueden convertir en unos alia- 
dos excelentes y a veces imprescindibles para garantizar la autocomprensión, el conocimiento profundo de uno mismo.

Y es que en el marco psíquico de estas experiencias se ponen de manifesto los vacíos del que las realiza, se activan los miedos y los deseos, las pulsiones y las esperanzas de manera mucho más intensa y viva que en las demás experiencias, sin las censuras que normalmente imponen la racionalidad y la conciencia. Se abre así el camino para el conocimiento del inconsciente, condición indispensable para el conocimiento profundo de la personalidad integral.

Platón habló de ello en cierta manera cuando se refirió al mundo de los sueños. Para el filósofo griego tan solo a través de las experiencias oníricas podemos descubrir la dimensión bestial, salvaje, que está adormecida en lo más profundo de nuestro psiquismo. Para él, en los sueños «el razonamiento y la vergüenza quedan en suspenso, y la bestia que hay en nosotros sale a satisfacer sus deseos» (Platón, 1981, libro IX, p. 281).

A partir de las aportaciones de Freud sabemos que, como en el resto de los fenómenos entre dos luces, en los sueños hay un proceso de simbolización, hay unos contenidos manifiestos bajo los que se esconden los latentes. Lo que aparece en la superficie es expresión de deseos y de temores profundos.

Para él, es convirtiendo los contenidos latentes en manifiestos como la persona puede lograr el insight, la comprensión profunda de su psiquismo. Paradójicamente, pues, mediante una adecuada vivencia de experiencias regresivas podemos realizar una madurativa.

\section{FENÓMENOS ENTRE DOS LUCES Y FORMAS DE CONOCIMIENTO}

Podríamos hablar de dos sistemas de simbolización: el que prima la fuerza de la racionalidad, y el que prima la fuerza de la emotividad (LeDoux, 1999 y Damasio, 1996). Ya se ha indicado que son dos sistemas diversos de significación, de construcción de sentido y de valor: en el primero se activan procesos secundarios; en el segundo, primarios. El sistema racional se fundamenta en la reflexión y en la argumentación. El segundo, en la asociación y en la transferencia emotiva. En el primero los procesos son siempre conscientes, mientras que en en el segundo a menudo son inconscientes. 
Precisamente por lo que comportan en cuanto a pérdida de peso de la racionalidad y de la conciencia, en los fenómenos entre dos luces la simbolización no se realiza a través de procesos secundarios sino primarios. En otras palabras, la construcción de sentido y de valor que realiza el sujeto es el resultado de simples procesos de asociación, de transferencias emotivas, por similitud o por contigüidad.

Se sabe que una de las características de los procesos mentales es la búsqueda instintiva, automática, del orden y del significado, en un mundo que con frecuencia se experimenta como vacío, confuso o amenazador. En aquellas situaciones en las que el inconsciente se impone sobre la conciencia y la emotividad sobre la racionalidad, o sencillamente cuando no se encuentran soluciones a los problemas en la razón y en la argumentación, el significado y el orden se buscan en las asociaciones y en las transferencias.

Un buen ejemplo son las supersticiones. Abundan las investigaciones que demuetran que el pensamiento supersticioso no establece diferencias de nivel cultural, lo que pone de manifiesto que el pensamiento primario o mágico convive en todos nosotros, personas civilizadas, con el secundario o lógico, aunque sea como rasgo periférico. Por otra parte, este tipo de pensamiento adquiere relevancia o preeminencia en experiencias en las que las emociones dominan sobre la racionalidad, y el inconsciente sobre la conciencia.

En efecto, está demostrado que las supersticiones se dan de manera preferente en situaciones de peligro o de riesgo: guerras, catástrofes, enfermedades, viajes largos, vuelos en avión, etcétera. En la misma línea, también está demostrado que los comportamientos supersticiosos se producen de manera preferente en sujetos que pertenecen a las profesiones más arriesgadas: soldados en tiempo de guerra, marineros, pilotos de aviación, etcétera.

Las supersticiones demuestran, pues, que el pensamiento mágico, el primario, no es patrimonio exclusivo de los pueblos primitivos, de los niños o de las personas sin cultura. Al respecto es significativo el caso del científico danés Niels Bohr, uno de los físicos más prestigiosos del siglo xx y premio Nobel. Bohr tenía colgada una gran herradura en una pared de su despacho. Cuando alguien, sorprendido, se atrevía a preguntarle si una persona de su nivel intelectual creía en aquellas cosas, respondía: «No, creer no creo, pero es que dicen que también influyen en las personas que no creen». 
Cuando en 1955 se produjo una amenazadora erupción volcánica en Hawai, incluso los ciudadanos con nivel cultural alto participaron en actividades aparentemente supersticiosas, como la de presentar ofrendas a la diosa del volcán arrojándolas sobre la corriente de lava.

\section{FENÓMENOS ENTRE DOS LUCES E IDENTIDAD PERSONAL}

En el fondo de los fenómenos entre dos luces existe, de alguna manera, la expresión de una necesidad, de un vacío, y, en consecuencia, de una búsqueda. Podríamos decir que en ellos se expresa, a menudo de manera inconsciente, la necesidad de complementar una personalidad deficitaria o de integrar una personalidad escindida, es decir, la necesidad de reconfigurar la identidad personal.

La identidad se construye dentro de la persona, donde conviven las representaciones que tenemos de nosotros mismos con las que tenemos de los demás. La adquisición del sentimiento de identidad es el resultado de una serie de interacciones, tanto con uno mismo como con los otros. La identidad se configura de manera integradora, interrelacionando vínculos de carácter espacial, temporal y social (Grinberg, 1993, p. 23).

Freud señaló las similitudes existentes entre las necesidades de identificación y las de nutrición. Consideraba que el primer comportamiento del niño hacia un objeto consiste en querer tragarlo. Decía textualmente: querer «consumirlo y recrearlo en el yo».

Tanto en la nutrición como en la identificación se trata de complementar, de llenar un vacío, de compensar unas insatisfacciones, de superar unas carencias. En la nutrición el objetivo de la experiencia es construir un cuerpo que tan solo está a medio hacer. En la identificación la meta es construir una personalidad que se experimenta como incompleta o disociada.

Melanie Klein parece estar muy cerca de la metáfora de la nutrición, cuando insiste en el hecho de que el desarrollo del yo se sustenta en buena medida en los objetos buenos internalizados, asimilados. Para Klein, la estructuración y la consolidación del yo incipiente se basan en alto grado en las identificaciones introyectiva y proyectiva. 
El niño aprende a distinguir entre cosas buenas y malas en función del grado de placer o de displacer que le proporcionan. A partir de aquí, el psiquismo infantil desarrolla un doble movimiento, centrífugo y centrípeto, que se mantiene también en el psiquismo del adulto. El movimiento psíquico de tipo centrífugo corresponde a la proyección, y consiste en rechazar o expulsar todo lo que se experimenta como desagradable. El de tipo centrípeto es de signo contrario, y corresponde a la introyección. Consiste en incorporar todo lo que se experimenta como placentero.

El hecho de que en los relatos audiovisuales convencionales (y en general en los literarios) se juegue con personajes buenos y malos, se justifica por esa doble necesidad psíquica: disponer de personajes vividos como negativos en los que poder proyectar todo lo que experimentamos en nuestro interior como desagradable, y contar con personajes vividos como positivos en los que poderse asimilar, porque representan valores que nos resultan placenteros.

\section{EL ESPECTÁCULO AUDIOVISUAL COMO} FENÓMENO ENTRE DOS LUCES

Está fuera de duda que la experiencia de ser espectador puede ser definida también como fenómeno entre dos luces. Como espectadores, muchas veces nos hemos descubierto a nosotros mismos sufriendo sin que nos encontremos en peligro. En tales casos, comprobamos que no sirve de nada que nos demos toda clase de argumentos para ahorrarnos el sufrimiento. No sirve que intentemos convencernos de que no estamos en peligro, de que es seguro que el filme acabará bien, de que el actor o la actriz no sufrieron al representar aquellas acciones (al contrario, se lo pasaron bien y cobraron una fortuna).

No sirve de nada; seguimos sufriendo. $Y$ es que nuestro inconsciente necesita creerse aquella historia para dar salida a pulsiones, deseos y temores. Es una prueba de que en la experiencia de ser espectador -como en los demás fenómenos entre dos luces- la emoción acaba siendo más fuerte que la razón, el inconsciente más que la conciencia, la fantasía más que la realidad.

El cine, que es un medio de proyección desde el punto de vista técnico, lo es también desde el psicológico. El cine, y en general los medios de masas audiovisuales, se ofrecen al espectador como oportu- 
nidades para que se puedan vivenciar contenidos emocionales reprimidos o insatisfechos. Permiten el doble movimiento centrífugo y centrípeto que se inauguró en la infancia, así como asimilarnos a un personaje que experimentamos como placentero, y desplazar o transferir hacia otro unas pulsiones o sentimientos negativos que rechazamos en nosotros mismos. «Toda obra de ficción es catártica», decía Ernesto Sábato.

Si estos medios se han convertido en una industria poderosa (una industria de las conciencias, en afortunada expresión de Hans M. Enzensberger), si funcionan como negocio, es en buena medida porque fascinan. $Y$ si nos sentimos fascinados por las historias que se nos comunican es porque de alguna manera descubrimos en ellas -con frecuencia inconscientemente- una puesta en escena de nuestros fantasmas interiores, de nuestros sentimientos en conflicto, porque nos ofrecen elementos que compensan nuestros deseos insatisfechos, y porque se convierten en depositarios que se hacen cargo de las angustias y de los temores que no podemos tolerar en nosotros mismos.

Podría decirse que los modelos mediáticos cumplen una función compensatoria o complementaria. Compensan las deficiencias de nuestra personalidad. Régis Debray (1994) lo decía de una manera muy sugerente: «¿No son las muñecas los ídolos de los niños, y los ídolos las muñecas de los adultos?». Tal vez por eso el escritor Mark Twain aseguraba que, si todo el mundo estuviera suficientemente satisfecho consigo mismo, no habría héroes. No harían falta.

\section{ESPECTÁCULO AUDIOVISUAL Y TRANSMISIÓN DE VALORES}

Pero los relatos de los medios de masas audiovisuales, como los sueños, como los demás fenómenos entre dos luces, no cumplen sólo una función expresiva, sino también modeladora. No sólo ponen de manifiesto nuestros vacíos, nuestras carencias. También los Ilenan. Al mismo tiempo que expresan y activan necesidades y deseos, los modelan y les dan una dirección, un sentido. En palabras de Edgar Morin (1972, p. 247), una fábrica de sueños es una fábrica de personalidad.

Como en los sueños, también en los relatos audiovisuales hay un proceso de simbolización y unos contenidos latentes enmascarados bajo los manifiestos. Y ese proceso de simbolización o de significación se realiza, como en los demás fenómenos entre dos luces, a través de 
transferencias emotivas. La atribución de sentido y de valor no se produce argumentando, aduciendo razonamientos, sino por simple asociación, por transferencia emotiva. Asimilan aquellos aspectos, aquellos atributos o propiedades que nos resultan placenteros. Los metabolizamos, los convertimos en sustancia de nuestra identidad.

Cuando se premia narrativamente -y por tanto con emotividad- a un personaje, a una acción o a una situación, se los está premiando desde los puntos de vista ideológico y ético. Cuando se los castiga narrativamente, se está haciendo desde las perspectivas ideológica y ética. La energía emotiva liberada por la historia, sea positiva o negativa, se canaliza en una dirección ideológica y ética.

Bastará un ejemplo. Durante muchísimo tiempo, los modelos femeninos que las mujeres encontraban en las pantallas, las heroínas en las que se podían reflejar, eran mujeres pasivas, resignadas, sometidas. Los modelos femeninos que premiaban emotivamente las historias convencionales eran mujeres que se sentían realizadas asumiendo un papel de dependencia. De esta manera, la sociedad mediática había estado potenciando y perpetuando este papel social femenino.

La prueba de que los efectos socializadores de tales medios tiene más que ver con la transferencia emotiva que con la argumentación o con el razonamiento, es la actitud regresiva con la que nos aproximamos a la experiencia mediática. No es que los espectadores vivamos como placentero lo que es bueno, sino que encontramos bueno lo que vivimos como placentero; no es que vivamos como desagradable lo que es malo, sino que encontramos malo lo que vivimos como desagradable.

Bastará también un ejemplo. Normalmente vivimos como placenteros a los representantes de la ley y del orden (la policía) y como desagradables a los de la delincuencia (ladrones o gángsters). Pero cuando los gángsters están interpretados por Paul Newman y Robert Redford (Dos hombres y un destino o El golpe), para que nos identifiquemos con ellos deseamos que tengan éxito en sus fechorías y sufrimos anhelando que la policía no consiga detenerlos.

En la primera infancia nos guiamos por el principio del placer: identificamos el bien con lo que resulta placentero o agradable, y el mal con lo desagradable. Al madurar, descubrimos el principio de la realidad, asumimos su complejidad, aprendemos a incorporar lo que es 
desagradable en el concepto del bien. En la experiencia mediática tendemos a retroceder, a volver al reduccionismo, a identificar el bien con una gratificación primaria, inmediata.

La personalidad se construye a partir de una serie sucesiva de identificaciones. Éstas se producen a partir de modelos que se viven como gratificantes. Teniendo en cuenta la capacidad de los medios de masas de convertir en gratificantes los modelos que presenta, habrá que concluir que de la sociedad mediática provienen muchos de los modelos humanos que acabamos interiorizando como positivos.

Goethe decía que somos modelados por lo que amamos. Ahora podríamos decir que somos modelados por los que dominan los medios capaces de hacernos amar lo que desean que amemos. Me refiero tanto a los que dominan las herramientas tecnológicas, como, sobre todo, a los que dominan los mecanismos psíquicos de la comunicación audiovisual. Podría parecer que el público sólo busca espectáculo. Pero la sociedad mediática, junto con el espectáculo, le ofrece, inevitablemente, sentido. A menudo sin que se de cuenta.

No es extraño, pues, que el novelista Ernest Hemingway dijera que una buena narración se parece a un iceberg: cuatro quintas partes están escondidas bajo el agua, y sólo una emerge. La fuerza emotiva y socializadora del relato audiovisual radica en el hecho de que, en gran medida, produce sus efectos fuera del control de la racionalidad y de la conciencia.

\section{LOS MODELOS CULTURALMENTE DISPONIBLES}

Los especialistas consideran que la identificación no tiene lugar con una persona, sino con una representación de esa persona. $Y$ esta es la tarea que realizan los medios de masas audiovisuales, unas veces de manera intencional y otras involuntaria: ofrecer representaciones personales con las que poder llenar los vacíos psíquicos que presentan los receptores.

Aprovechando el símil freudiano de la nutrición, podría afirmarse que cada cultura llena los vacíos del psiquismo con un régimen alimenticio distinto. Cada cultura ofrece un repertorio limitado y definido de modelos, un repertorio en el que se ponen de manifiesto los valores que se cotizan en aquella cultura. 
La importancia de los modelos o de los mitos socialmente disponibles es capital, porque con ellos es con los que se construye el imaginario colectivo, y es mediante este imaginario como alimentamos nuestro espíritu y vamos configurando nuestra identidad. El que se alimenta siempre de carne difícilmente se convertirá en vegetariano. La cultura nos marca, para bien o para mal, imponiendo como modelos unas determinadas representaciones humanas.

Al dar respuesta a necesidades emotivas, los modelos también la dan a necesidades cognitivas. Los modelos imperantes, al Ilenar carencias emotivas, satisfacen, con intención o sin ella, consciente 0 inconscientemente, necesidades de sentido (Ferrés, 1996, p. 125). Era muy inteligente aquel que decía que no le importaba quién hiciera las leyes de una sociedad mientras él pudiera crear sus mitos.

Podríamos entonces definir las culturas por el tipo de héroes 0 de mitos que privilegian. Por ejemplo, hay diferencias sustanciales entre la cultura de la Grecia clásica, con un mito como Ulises; la cultura del mundo cristiano, con el mito central de Jesucristo; la cultura hispana medieval, con mitos como el Cid Campeador y la cultura contemporánea, con los efímeros e insustanciales mitos de la postmodernidad.

Hollywood y la publicidad son, sin duda, los responsables de construir los modelos comunicativos que más han contribuido a configurar el imaginario colectivo del siglo xx. Hollywood ha sido bautizado como la fábrica de sueños. La publicidad, por su parte, es un modelo comunicativo que lo impregna todo, en el sentido de que interfiere físicamente en todos los demás discursos, en el de que es un modelo que todo lo fagocita, y en que él mismo es contínuamente imitado.

Pues bien, tanto Hollywood como la publicidad parecen responsables de haber nutrido el imaginario colectivo occidental con unos modelos de belleza y de comportamiento muy alejados de la realidad, imponiendo unos estándares inalcanzables.

\section{LOS MODELOS INASEQUIBLES DE LOS MEDIOS DE MASAS}

Rita Hayworth solía decir, con una irónica lucidez y una reconfortante capacidad de autocrítica: «Los hombres se van a la cama con Gilda y se despiertan con Rita Hayworth». De hecho, podríamos ir un poco más lejos y distinguir entre Gilda (el personaje), Rita Hayworth (la 
actriz que la interpretaba) y Margarita Carmen Cansino (la mujer que había bajo la actriz). Los sueños y las fantasías de los espectadores se limitaban, si acaso, a las dos primeras. Con una lucidez y una ironía similares se expresaba Cary Grant, el eterno galán: «A todo el mundo le gustaría ser Cary Grant, incluso a Cary Grant».

La televisión, y todavía más la publicidad, parecen haberse propuesto llevar al extremo estas tendencias. En Barcelona, una de las ciudades punteras de la publicidad mundial, hay sólo tres modelos que prestan sus manos, de manera que, cuando en un anuncio hace falta un plano detallado de unas manos femeninas, se recurre a las de una de estas tres modelos.

Eso significa que las impresionantes mujeres que se nos ofrecen como modelos en los anuncios no existen ni siquiera en el mundo de la publicidad. Son el resultado de una artificiosa combinación de fragmentos: la cara es de una, el cuerpo de otra, las manos de una tercera... y la voz de una cuarta. Son lo que podríamos denominar mujeres-puzzle, que satisfacen pulsiones escópicas y carencias emocionales, pero que al mismo tiempo nutren el imaginario individual y colectivo con un régimen alimenticio cuando menos cuestionable, imponiendo un ideal de belleza inasequible, irrealizable.

En este contexto es inevitable pensar en el problema de la anorexia. Con su reflejo, la potencian, la legitiman. La anorexia es un problema creciente: se incrementa un 15\% cada año. En estos momentos afecta ya a sectores sociales que antes le eran ajenos: no sólo a las chicas, cada vez más a los chicos; no sólo a los adolescentes, sino a los niños. El cine y la publicidad no son los culpables, pero tampoco puede decirse que se limiten a reproducir las tendencias imperantes en la sociedad.

Y no se trata sólo de la anorexia. Según una encuesta reciente, uno de cada cuatro chicos no está satisfecho con su cuerpo. La distancia creciente entre los modelos físicos y la realidad desemboca en frustraciones y en depresiones.

Pero más allá de la apariencia física, los modelos mediáticos de la postmodernidad son negativos porque no asumen la complejidad psíquica, las contradicciones que definen la naturaleza humana. Los modelos de la postmodernidad son vacíos, sin densidad humana, sin complejidad, de una sola pieza. 
No se trata de añorar tiempos pasados, pero hay que admitir que los modelos de identificación han ido perdiendo consistencia, han perdido densidad humana. Los mitos clásicos a los que hemos hecho referencia eran más sólidos, más consistentes. Tenían el peso específico de la complejidad, de la asunción de las contradicciones. Incorporaban a su grandeza las dimensiones de la oscuridad: la debilidad, el sufrimiento, la muerte.

Los modelos de la cultura mediática no suelen incorporar la carencia, la finitud, la fragilidad, y todavía menos el sufrimiento y la muerte, elementos constitutivos de la naturaleza humana. Y, si los incorporan, los acaban negando. El discurso publicitario, por ejemplo, presenta los objetos de consumo no como solución de carencias funcionales (limpieza, vestuario, alimentación...), sino como respuesta a los interrogantes más trascendentes. Banalidad total, porque los modelos publicitarios garantizan soluciones mágicas y sin ninguna clase de esfuerzo para los problemas más radicales: los que hacen referencia a la felicidad, al amor, a la identidad personal, a la personalidad, a la libertad, al sentido de la vida.

Podría alegarse también que en relatos tradicionales, como los cuentos de hadas, se recurría a soluciones mágicas: finales felices que llegaban de manera milagrosa. Pero en aquellos casos hacía falta que los protagonistas hubieran hecho un descenso a los infiernos, que hubieran recorrido un largo y doloroso itinerario, que hubieran participado en un ritual iniciático, que hubieran superado unas duras pruebas o vencido unos obstáculos en apariencia insuperables. En los modernos cuentos de hadas, en cambio, las soluciones mágicas no exigen otro esfuerzo que el de casarse con unos productos asequibles y seductores: la libertad es una marca de teléfono móvil, el amor una colonia, la identidad la dan unos tejanos, el sentido de la vida se encuentra en un yogur, la felicidad en una compresa.

Seguramente es por esa inconsistencia que tales modelos no acaban de cuajar; conectan sólo con las dimensiones más superficiales del psiquismo. Y por eso son abandonados y sustituidos con tanta facilidad. La postmodernidad utiliza modelos de usar y tirar. Compensa con la cantidad la falta de calidad.

\section{LA FUNCIÓN EDUCATIVA DE LOS MEDIOS}

Los medios de comunicación de masas tienen un indiscutible efecto educativo, tanto cuando es intencional como cuando es involun- 
tario. Son educadores, para bien o para mal. Hablo de educar en el sentido etimológico del término: e-ducere es sacar de dentro hacia fuera, sacar a alguien de sí mismo, ayudarle para que se mueva, impulsarle a ir más allá de sí mismo, apoyarle en el desarrollo de lo que ya está en él de manera embrionaria, hacer surgir lo que está de manera latente, como en el revelado de las fotografías.

Teniendo en cuenta la doble función que cumplen los medios -la de reflejo y la de moduladores-, y el carácter fronterizo de la experiencia de ser espectador, la educación en medios se debería plantear, ante todo, por qué gusta un mensaje audiovisual, por qué resulta gratificante, qué instintos satisface, si son positivos o negativos, constructivos o destructivos. Sólo desde esa toma de conciencia podrá el sujeto descubrir cuáles serán los efectos del mensaje, es decir, cómo contribuirá a modelar la conciencia aplicando los criterios de la lógica transferencial.

Como en el caso de la educación nutricional, los efectos de los modelos mediáticos que consumimos serán muy diferentes en función de que sepamos o no cuál es la dieta más adecuada, y cuál es la mejor manera para digerir lo que consumimos.

En síntesis, los educadores deberíamos comprometernos con la educación en medios, pero asegurándonos de que impartimos un tipo de educación que tiene en cuenta las cuatro quintas partes escondidas del iceberg de los relatos audiovisuales. 0, mejor, que toma en consideración las cuatro quintas partes sumergidas del iceberg mental. En otras palabras, una educación que atienda las dimensiones emotiva e inconsciente de la experiencia de ser espectador, a fin de convertir lo inconsciente en consciente, las emociones en reflexiones, lo que exige que la educación en medios debe conceder mucha más importancia a la competencia emocional.

Sólo así será eficaz. Sólo así se podrá facilitar una adecuada nutrición que garantice un crecimiento equilibrado de la personalidad.

\section{BIBLIOGRAFÍA}

AgUILAR, P. (1996): Manual del espectador inteligente, Madrid, Fundamentos, col. Arte, serie Imagen. 
Alonso, M. y MatilLA, L. (1990): Imágenes en acción. Análisis y práctica de la expresión audiovisual en la escuela activa, Madrid, Ediciones Akal.

Alonso, M.; Matilla, L. y VÁZquez, M. (1995): Teleniños públicos/Teleniños privados, Madrid, Ediciones de la Torre, col. Proyecto Didáctico Quirón, núm. 66.

ApARICI, R. y GARCÍA-MATILLA, A. (1987): Lectura de imágenes, Madrid, Ediciones de la Torre, col. Proyecto Didáctico Quirón, núm. 6.

DAmASIO, A. R. (1996): El error de Descartes. La emoción, la razón y el cerebro humano, Barcelona, Crítica, Grijalbo Mondadori, col. Drakontos, Paidós Studio.

DANZER, R. (1989): Las emociones, Barcelona, Ediciones Paidós Ibérica, col. celona, Labor.

ERdely, M. H. (1990): Psicoanálisis. La psicología cognitiva de Freud, Bar-

FERRÉS, J. (1996): Televisión subliminal. Socialización mediante comunicaciones inadvertidas, Barcelona, Ediciones Paidós Ibérica.

FREUD, S. (1985): La interpretación de los sueños, Barcelona, Planeta.

FREUD, S. (1968): El malestar de la cultura, Obras completas, vol. VIII, Madrid, Biblioteca Nueva.

68 Bitácora.

García Matilla, E. (1990): Subliminal: escrito en nuestro cerebro, Madrid, Libro de Bolsillo. Plaza \& Janés.

Goleman, D. (1997): El punto ciego. Psicología del autoengaño, Barcelona,

— (1996): Inteligencia emocional, Barcelona, Kairós. teca Nueva.

GonZÁLEZ, J. L. (1988): Persuasión subliminal y sus técnicas, Madrid, BiblioPaidós Ibérica.

GRINBERG, L. y R. (1993): Identidad y cambio (2a ed.), Barcelona, Ediciones

Gubern, R. (1993): Espejo de fantasmas. De John Travolta a Indiana Jones, Madrid, Espasa Calpe.

JÁUREGUI, J. A. (1998): Cerebro y emociones. El ordenador emocional (2a ed.), Madrid, Maeva Ediciones.

JUNG, C. G. (1994): La interpretación de la naturaleza y la psique. La sincronicidad como un principio de conexión causal ( $3^{\mathrm{a}}$ reimpr.), Barcelona y Buenos Aires, Ediciones Paidós Ibérica, y Editorial Paidós, SAICF (Biblioteca de Psicología Profunda), 12.

KEY, W. B. (1991): Seducción subliminal, Buenos Aires, Vergara y Diana. 
rial Planeta.

LEDoux, J. (1999): El cerebro emocional, Barcelona, Editorial Ariel y Edito-

LYONS, W. (1993): Emoción, Barcelona, Anthropos Editorial del Hombre, col. Autores, Textos y Temas Filosofía.

MorIN, E. (1972a): El cine o el hombre imaginario, Barcelona, Seix Barral.

— (1972b): Las stars. Servidumbres y mitos, Barcelona, Dopesa.

PLATón (1981): Obras completas ( $2^{\mathrm{a}}$ ed.), Madrid, Aguilar.

Postman, N. (1991): Divertirse hasta morir, Barcelona, Editorial de la Tempestad.

UNESCO (2002): Youth and Media, París.

Younis HeRnÁndez, J. A. (1993): El aula fuera del aula, Las Palmas de Gran Canaria, Librería Nogal Ediciones. 